\title{
Induction and Prevention of Gastric Cancer with Combined Helicobacter Pylori and Capsaicin Administration and DFMO Treatment, Respectively
}

\author{
Faisal Aziz ${ }^{1,2}$, Mingxia Xin ${ }^{2}$, Yunfeng Gao ${ }^{2}$, Abhijit Chakroborty ${ }^{1}$, Imran Khan ${ }^{1}$, Josh Monts ${ }^{1}$, \\ Kjersten Monson ${ }^{1,3}$, Ann M. Bode ${ }^{1}$ and Zigang Dong ${ }^{1, *}$ \\ 1 The Hormel Institute, University of Minnesota, Austin, MN 55912, USA; faziz@umn.edu (F.A.); \\ aabhi.mn@gmail.com (A.C.); khan0672@umn.edu (I.K.); jmonts@cores.utah.edu (J.M.); \\ kjm47223@bethel.edu (K.M.); bodex008@umn.edu (A.M.B.) \\ 2 China-US (Henan) Cancer Institute, Zhengzhou, Henan 450003, China; mxxin@hci-cn.org (M.X.); \\ yfgao@hci-cn.org (Y.G.) \\ 3 Department of Ophthalmology, Mayo Clinic, Rochester, MN 55902, USA \\ * Correspondence: zgdong@hci-cn.org
}

Received: 9 March 2020; Accepted: 26 March 2020; Published: 28 March 2020

\begin{abstract}
Gastric cancer risk evolves over time due to environmental, dietary, and lifestyle changes, including Helicobacter pylori (H. pylori) infection and consumption of hot peppers (i.e., capsaicin). $H$. pylori infection promotes gastric mucosal injury in the early phase of capsaicin exposure. This relationship suggests a need to investigate the mechanism of how both $H$. pylori infection and capsaicin contribute to gastric inflammation and lead to gastric cancer. C57-Balb/c mice were infected with the H. pylori (SS1) strain and then fed capsaicin $(0.05 \%$ or $0.2 \mathrm{~g} / \mathrm{kg} / \mathrm{day})$ or not. Consequently, tumor size and phenotype were analyzed to determine the molecular mechanism driving the shift from gastritis to stomach cancer. Moreover, we used 2-difluoromethylornithine (DFMO) in mice to prevent gastric tumorigenesis by reducing inflammation and promoting recovery of disease-free stasis. This study provides evidence showing that a combination of $H$. pylori infection and capsaicin consumption leads to gastric carcinogenesis mediated through interleukin-6 (IL-6) stimulation with an incidence rate of 50\%. The anti-inflammatory role of DFMO highlights the injurious effect of inflammation in gastric cancer development and the need to reduce gastric inflammation for cancer prevention by inhibiting IL-6. Accordingly, preventive measures such as reduced capsaicin consumption, $\mathrm{H}$. pylori clearance, and DFMO treatment may lessen gastric cancer incidence.
\end{abstract}

Keywords: capsaicin; DFMO; gastric inflammation; gastric cancer; Helicobacter. pylori; IL-6

\section{Introduction}

The Centers for Disease Control and Prevention estimates that roughly two-thirds of the population of the world harbor Helicobacter pylori (H. pylori), a bacterium that colonizes the stomach and duodenum [1,2]. Without treatment, H. pylori infection is a known risk factor for gastrointestinal illnesses like chronic gastritis, peptic ulcers, and stomach cancer [3-5]. In 2001, an epidemiologic study demonstrated that patients infected with $H$. pylori were nearly six times more likely to develop gastric cancer compared to uninfected people. Other gastric cancer risk factors include host [6,7], dietary, and lifestyle practices including capsaicin consumption, stress levels, and ingestion of inflammatory foods or beverages. In summary, the etiology of gastric cancer is influenced by bacterial variability, along with host genetic and environmental factors; however, the molecular mechanisms governing these factors have not been fully elucidated [8-11]. 
Evidence suggests that $H$. pylori infection impacts the development and progression of gastric mucosal injury during early capsaicin exposure from hot pepper consumption [12]. Capsaicin reportedly suppresses immune function and increases host susceptibility to infection [13-15]. Other data suggest an epidemiological link between stomach cancer incidence and chili pepper-rich diets $[12,16]$. In contrast, several studies reported the anti-cancer and anti-inflammatory effects of capsaicin that activate the expression of several genes involved in the inhibition of cancer cell survival, growth arrest, angiogenesis, and metastasis [17-20]. Ultimately, capsaicin's role in carcinogenesis remains controversial. Additionally, synergism between $H$. pylori and other factors is not often the focus of studies. This neglected interplay between $H$. pylori infection and other agents may be critical to the initiation and persistence of gastric inflammation, as well as the development of gastric cancer. Here, we explore the combined effect of $H$. pylori infection and capsaicin exposure on the development of gastritis and gastric carcinogenesis, as well as possible anti-inflammatory regimens for disease prevention. The selected anti-inflammatory agent, DFMO (2-difluoromethylornithine), reportedly alters immune populations within the tumor microenvironment and inhibits tumor growth by increasing $\mathrm{CD}^{+}$infiltration [21,22]. Despite its chemopreventive potential, the anti-inflammatory and anti-cancer effects of DFMO against gastritis and gastric cancer are unknown.

Additionally, the role of capsaicin consumption in the development of gastritis and gastric cancer has not been experimentally elucidated before now. Here, we explore the combined effect of H. pylori infection and capsaicin consumption on the development of gastritis and, later, gastric cancer. Lastly, we highlight DFMO as an anti-inflammatory treatment against gastritis and as a preventative measure against gastric carcinogenesis.

\section{Results}

\subsection{Capsaicin and H. pylori Infection Induce Gastritis Leading to Gastric Cancer}

To investigate the role of capsaicin consumption in the progression of H. pylori-associated gastric cancer, we developed a mouse model treated with a combination of capsaicin and H. pylori infection-induced gastritis, leading to gastric cancer. Macroscopic morphometric analysis revealed that capsaicin consumption induced gastric inflammation (at 32 weeks) as the initiating process, which led to tumor development (at 52 weeks) in the stomachs of mice with H. pylori infection (Figure 1b). Tumor growth in mice treated with both capsaicin and H. pylori confirmed the role of a combination of capsaicin and H. pylori in gastric tumorigenesis. Macroscopic analysis of tumor area revealed the development of tumors only in mice treated with both $H$. pylori and capsaicin $\left(30.26 \pm 7.017 \mathrm{~mm}^{2}\right.$; $p<0.0001$; Figure 1c). Mice treated with a combination of H. pylori and capsaicin showed significantly lower body weight compared to untreated mice (Figure 1d). Overall, these results indicated that H. pylori and capsaicin together caused a progressive shift from gastritis to gastric cancer. These results provided experimental animal evidence showing the combined effect of capsaicin and H. pylori infection on the development of gastric cancer. Histological analysis also showed multifocal elongation of the gastric pits, glandular atrophy, and a significant reduction in the glandular zone in atrophic foci. These changes were significantly less in mice treated with capsaicin and infected with $H$. pylori exhibiting tumors $(0.2 \pm 0.2 ; p<0.0001)$, compared to mice treated with only capsaicin $(2.60 \pm 0.24$; $p=0.02)$ or infected with $H$. pylori only $(1.0 \pm 0.316 ; p=0.0002$; Figure S1a-d). 

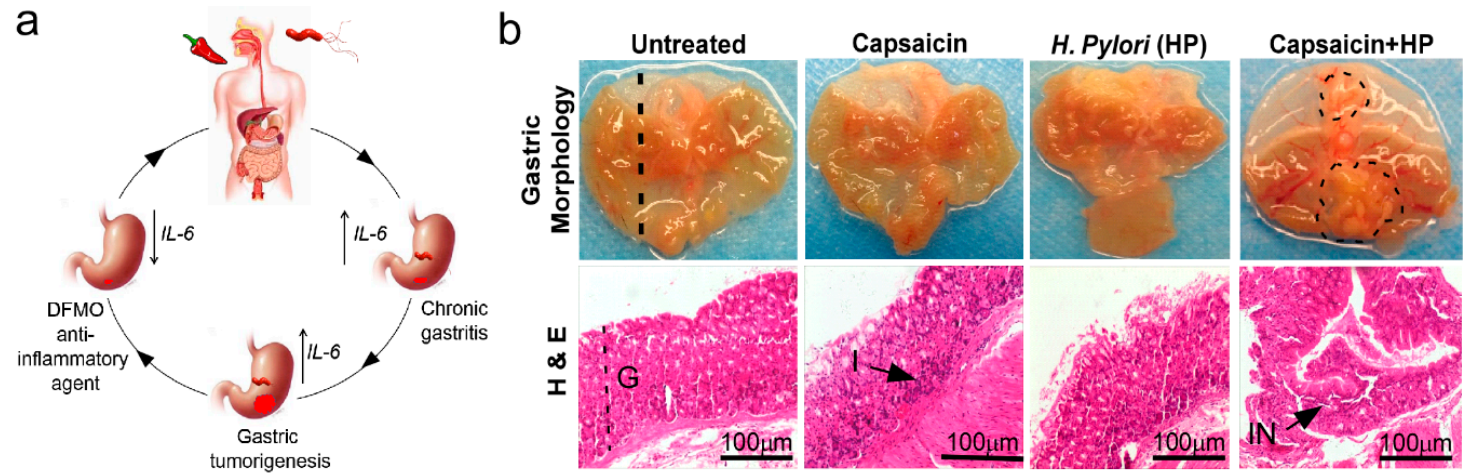

C

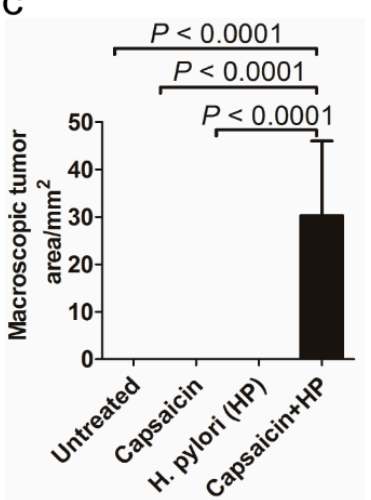

d

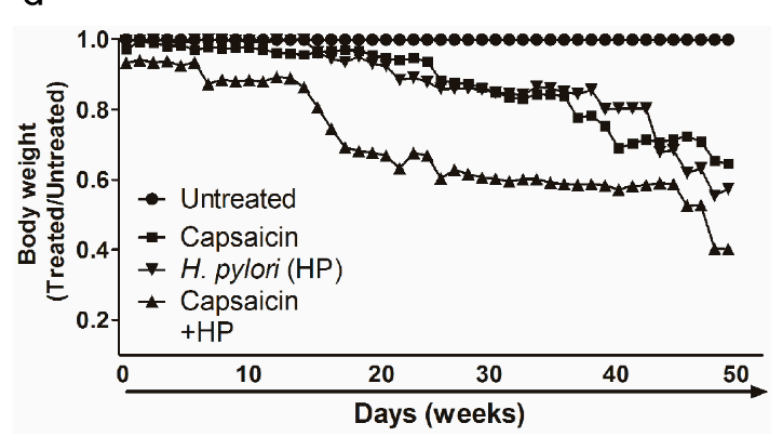

e

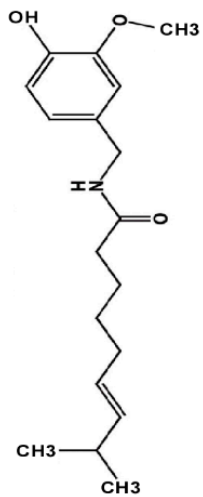

Figure 1. Development of mouse models for capsaicin- and H. pylori-induced progression of gastritis to gastric cancer. (a) Schematic drawing showing the effect of capsaicin consumption and H. pylori infection in the development and progression of gastritis to gastric tumorigenesis mediated through the stimulation of IL-6. (b) Macroscopic (top) and histologic (bottom) analyses of gastric mucosae ( $n=5 /$ cohort). Images of tumors at 52 weeks from mice infected with H. pylori and treated with capsaicin; tumor areas are outlined with dotted circles. Hematoxylin \& eosin (H\&E)-stained cross-sections are cut along the fundus to the proximal end of the corpus, as shown by the straight dotted line. Gastric pathology was substantially changed after 32 or 52 weeks of combination treatment with H. pylori and capsaicin. The panels are magnified $10 \times($ bar, $100 \mu \mathrm{m})$ and $40 \times($ bar, $20 \mu \mathrm{m})$. Arrow and $\mathrm{G}=$ glandular zone, $\mathrm{I}=$ inflammatory cells, $\mathrm{IN}=$ muscular mucosae invasion. (c) The size of gastric tumors from mice treated with capsaicin and infected with $H$. pylori compared to mice treated with only capsaicin or H. pylori is shown. (d) Effect of capsaicin, H. pylori, or a combination of capsaicin with $H$. pylori infection on mouse body weights. Body weights are shown as treated/untreated. (e) The chemical structural of capsaicin. Data are expressed as mean values \pm SEM, $(n=5 /$ cohort).

\subsection{Mice Treated with Capsaicin and H. pylori Exhibited Increased Gastric Atrophy and Accelerated Tumor Growth}

Histologic analysis revealed significant glandular atrophy in the fundi of mice at 32 weeks of a combination treatment with capsaicin and H. pylori compared with untreated mice or mice treated only with capsaicin or H. pylori (Figure 2). Dual treatment resulted in a reduction of parietal cell components, especially parietal and chief cells, which were replaced by gastric mucus-producing cells. Pepsinogen I and II, gastrin, somatostatin (gastric endocrine regulators), and $\mathrm{H}+/ \mathrm{K}+$ ATPase (parietal and chief cells) showed substantially lowered expression in mice exhibiting gastric tumorigenesis compared with untreated mice or mice treated singularly $(0.264 \pm 0.09 ; p<0.0001$; Figure 2a-f). Gastrin, somatostatin, and $\mathrm{H}+/ \mathrm{K}+$ ATPase are required for normal gastric mucosal development and parietal cell activation $[23,24]$. In mice exhibiting carcinogenesis, these biomolecules were almost completely ablated. As a result, a combination of capsaicin and H. pylori directly accelerated loss of differentiated epithelial cell types, leading to chronic atrophic gastritis and eventually to gastric tumorigenesis. The combination treatment shifted gastric tissue to a tumor phenotype with increased 
numbers of inflammatory cells found in the tumor gastric mucosa. This observation suggests that H. pylori or capsaicin alone is not enough to cause gastric tumorigenesis and that a combination is required to trigger the formation of submucosal glands and invasion of tumor cells.

a

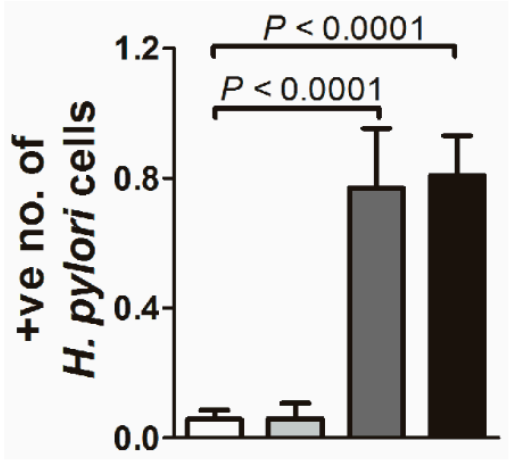

C

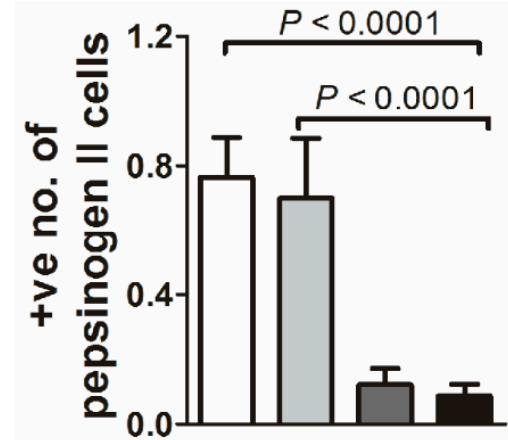

e

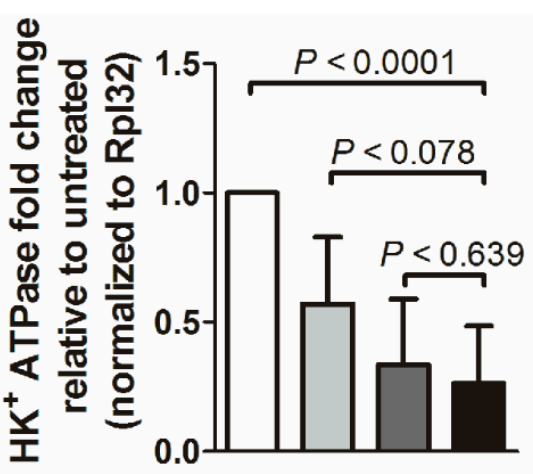

b
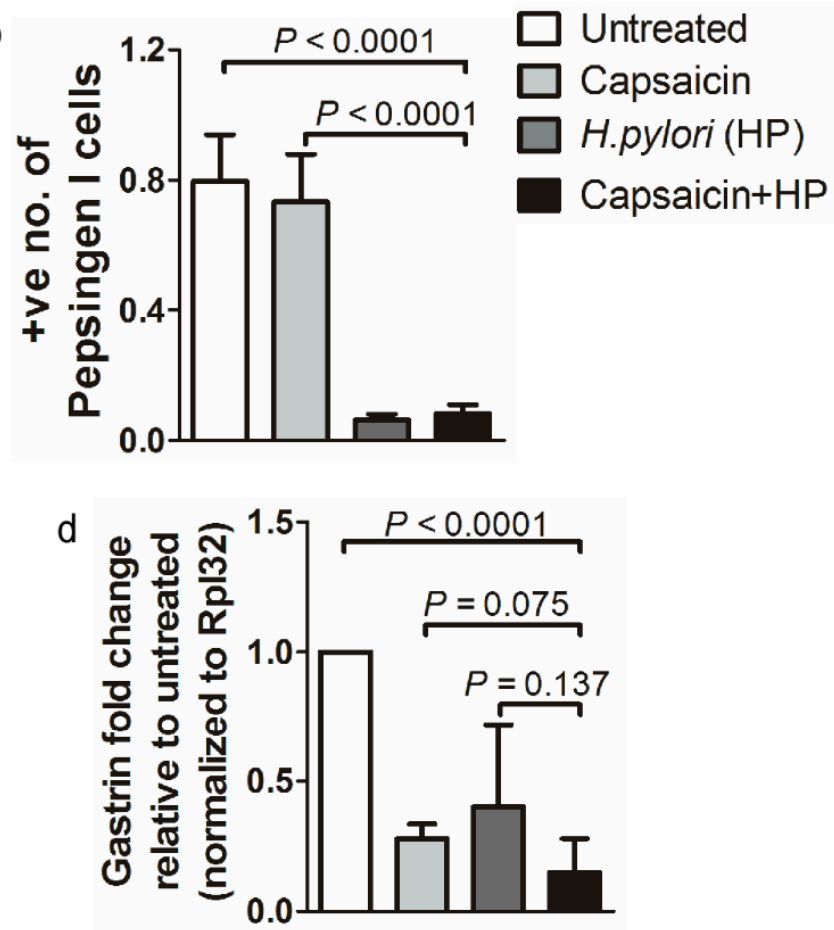

f

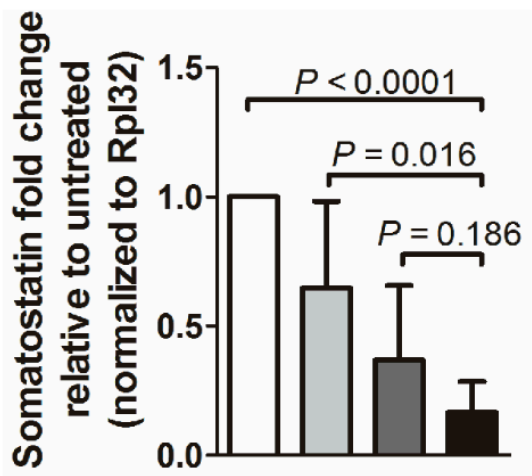

Figure 2. Immunohistochemical and $\mathrm{qPCR}$ analysis of gastric disease mouse models. Immunohistochemical detection of pepsinogen I and II and H. pylori expression in gastric tissues from mice treated with both capsaicin and H. pylori. Paraffin-embedded gastric tissues were stained to detect H. pylori, pepsinogen I, or pepsinogen II, respectively. Quantitative immunohistochemical detection of (a) H. pylori, (b) pepsinogen I, or (c) pepsinogen II expression. A strong intensity was observed in untreated gastritis tissue compared to gastric cancer tissues. Scale bars represent $100 \mu \mathrm{m}(10 \times)$, and the scale bar in the inset images represents $20 \mu \mathrm{m}(40 \times)$. A score of 1 denotes the highest staining, whereas a score of 0 indicates negative staining. mRNA analysis of (d) gastrin, (e) $\mathrm{H}^{+} \mathrm{K}^{+}$ATPase, and (f) somatostatin by qPCR. Average fold change in mRNA relative to untreated control ( $n=5 /$ cohort). 


\subsection{Diminished Expression of Tumor Suppressor Genes Coincided with Accelerated Tumorigenesis}

The effect of a combination of capsaicin and H. pylori was associated with increased tumor progression accompanied by substantially reduced expression of several gastric tumor suppressor genes (TSGs), including Tff1 by qPCR (0.273 \pm 0.120$)$, Tff2 (0.126 \pm 0.078$),$ Gkn1 $(0.143 \pm 0.045)$, and Gkn2 $(0.172 \pm 0.060)$ in the group of mice that developed tumors compared to other groups $(p<0.0001$; Figure S2a-d). Loss of these gastric-specific TSGs promotes tumorigenesis [25-27]. Tff1 and Tff2 genes are upstream regulators of gastrokine (Gkn) gene expression. The GKN2 protein exists as a heterodimer with Tff1, and the Tff2 genes are upstream regulators of gastrokine (Gkn) gene expression. Therefore, loss of Tff1 or Tff2 expression (TFFs peptides) could lead to tumor growth [28]. Overall, inhibition of Tff1, Tff2, Gkn1, and Gkn2 is known to be associated with tumorigenesis [28,29]. Gkns are gastric tissue-specific Tsgs, which are affected by H. pylori, cytokines, and Tff. Gkns are highly expressed in normal gastric tissues and downregulated in gastric cancer. Overexpression of Gkn2 could be associated with the prognosis of gastric cancer patients, as shown to inhibit gastric cancer cell proliferation, migration, and invasion [30-32]. TFF peptides (TFF1, TFF2, and TFF3) are involved in several steps of gastric cancer development through multiple oncogenic pathways and are considered to be potential tumor suppressor genes, including PI3-kinase, phospholipase C (PLC), MAPK, PKC, and the rapamycin target mTOR, but also EGF-R, COX-1, COX-2, and G-protein coupled receptors [33-36].

\subsection{Mice Administered Capsaicin and H. pylori Displayed Increased Gastric Tissue Damage}

The extent of gastric tissue damage was evaluated as well. We found that mice treated simultaneously with capsaicin and H. pylori exhibited tumor development. These mice displayed significantly higher activities of malondialdehyde (MDA; $401.100 \pm 45.33 \mathrm{mg} / \mathrm{mL} ; p<0.01$ ), myeloperoxidases (MPO; $0.402 \pm 0.050 \mathrm{U} / \mathrm{L} ; p<0.0001)$, catalase $(30.47 \pm 2.645 \mathrm{U} / \mathrm{mL} ; p=0.018)$, carbonyl $(220.4 \pm 37.35 \mathrm{nmol} / \mathrm{mg} ; p<0.001)$, and lipoperoxidase (LPO; $601.6 \pm 31.61 \mu \mathrm{mol} / \mathrm{L} ; p<0.0001)$ compared to mice treated with combination of $H$. pylori and capsaicin (Figure 3a-e). A combination of capsaicin and $H$. pylori infection increases peroxidation processes and leads to the production of superoxide radicals such as MDA, MPO, and hydrogen peroxide, which can form adducts with DNA and proteins. Subsequently, we proposed that $H$. pylori infection and capsaicin metabolites, including vanillylamine and vanillic acid and peroxides damage DNA, DNA-repair enzymes, and immune cell protein cytokines, resulting in gastric tissue damage [37-39].

\subsection{The Mouse-Derived Xenograft Model (MDX) Confirmed the Efficacy of the H. pylori-and Capsaicin-Associated Gastric Cancer Model}

To further elucidate the effect of capsaicin intake and H. pylori infection on the development of gastric cancer, we used gastric tumors from mice treated with both $H$. pylori and capsaicin to develop a mouse xenograft model (MDX). We successfully developed the MDX model with tumors at the first $(\mathrm{M} 1=100 \%)$ and second $(\mathrm{M} 2=100 \%)$ passages (Figure $4 \mathrm{a}-\mathrm{d})$. Histological analysis further confirmed the tumorigenicity and gastric origin of this combination by showing high expression levels of cytokeratin (PCK-26; $0.797 \pm 0.026,0.682 \pm 0.025,0.761 \pm 0.072)$, CD-34 (0.730 $\pm 0.067,0.722 \pm 0.030$, $0.749 \pm 0.035)$ and low expression levels of SMA- $\alpha(0.092 \pm 0.017 \mathrm{~s}, 0.046 \pm 0.013,0.099 \pm 0.017)$ in M0, M1, and M2 tumor tissues, respectively ( $p<0.001$; Figure 4) [40,41]. PCK-26, CD-34, and SMA- $\alpha$ were used to confirm the tumorigenicity in the stomach. SMA- $\alpha$ and PCK-26 were investigated to detect the smooth muscle and non-epithelial (sarcomas) characteristics of the stomach, respectively, which showed the development of tumorigenicity. 
a

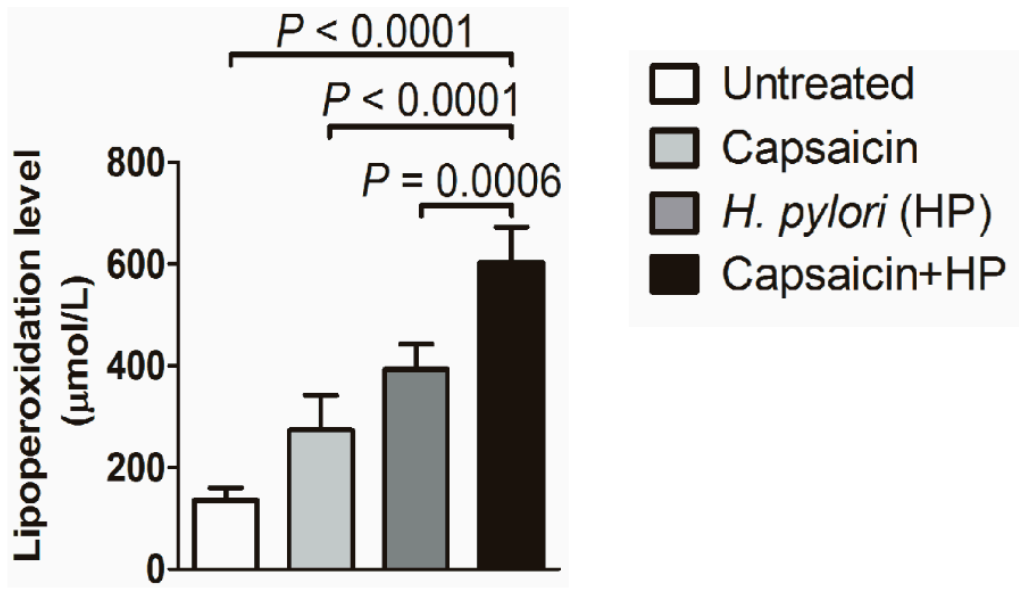

b

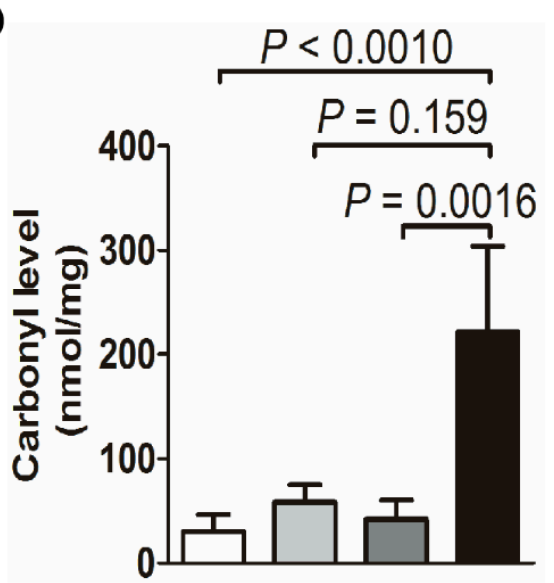

d

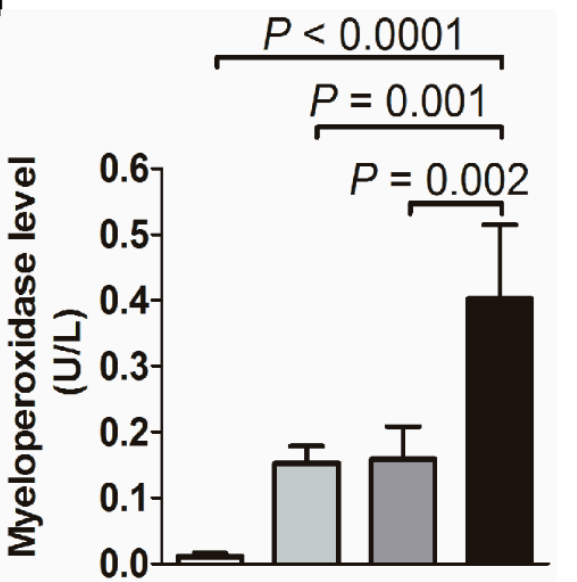

C

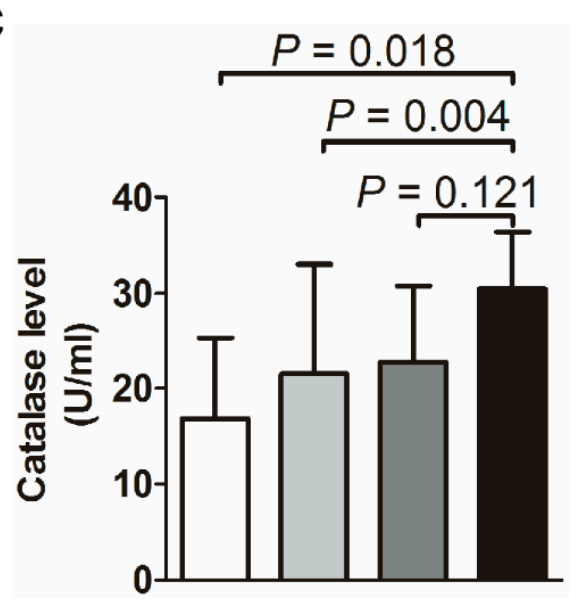

e

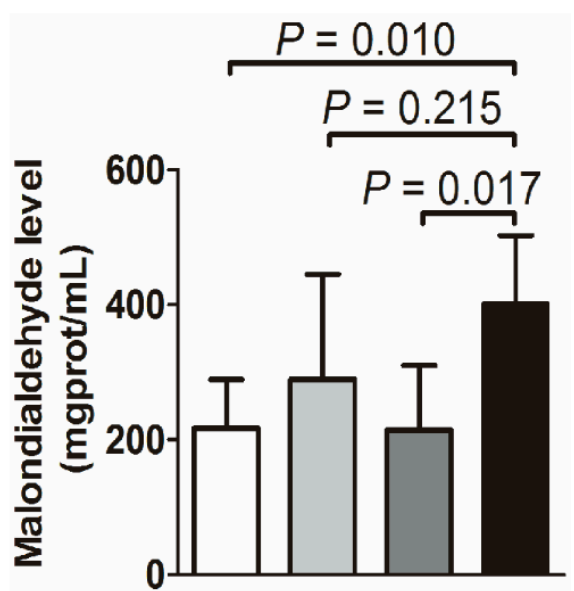

Figure 3. The level of tissue damage in gastric mucosa from gastric disease mouse models. Biochemical activity of (a) lipoperoxidase (LPO), (b) carbonyl, (c) catalase, (d) myeloperoxidases (MPO), and (e) malondialdehyde (MDA) in mice. Mice exhibiting gastritis or tumorigenesis show higher biochemical activity of these parameters compared to mice treated with capsaicin or H. pylori only ( $n=5 /$ cohort). 
a

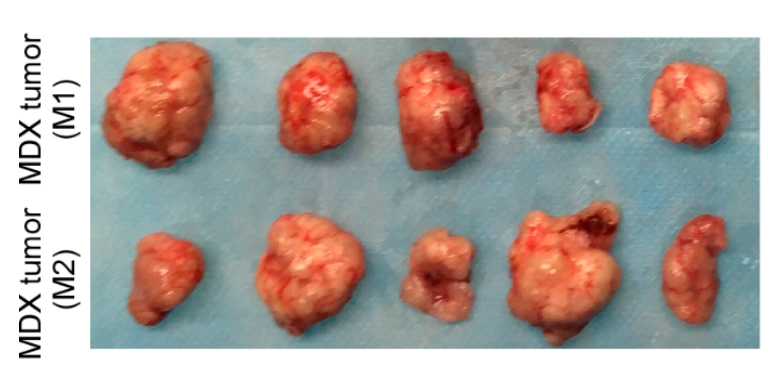

$\mathrm{b}$

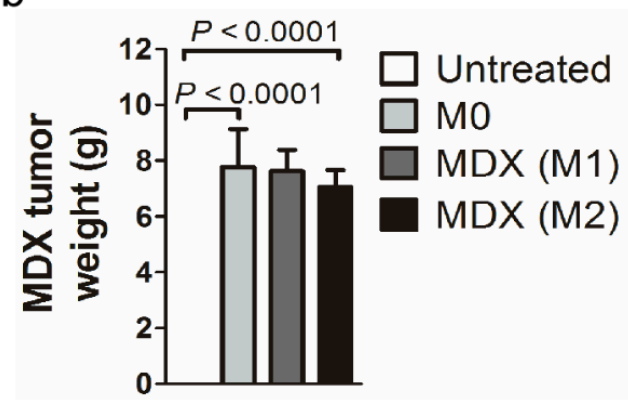

C

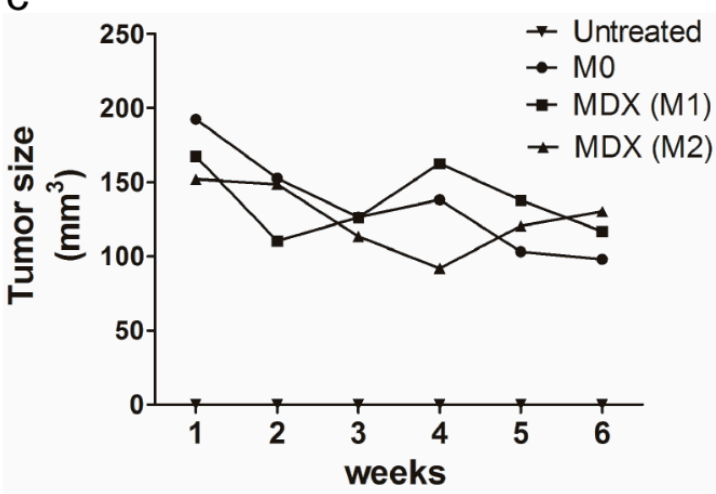

d

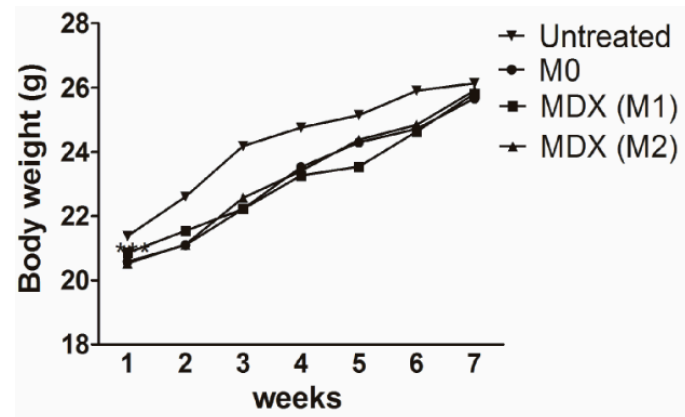

e

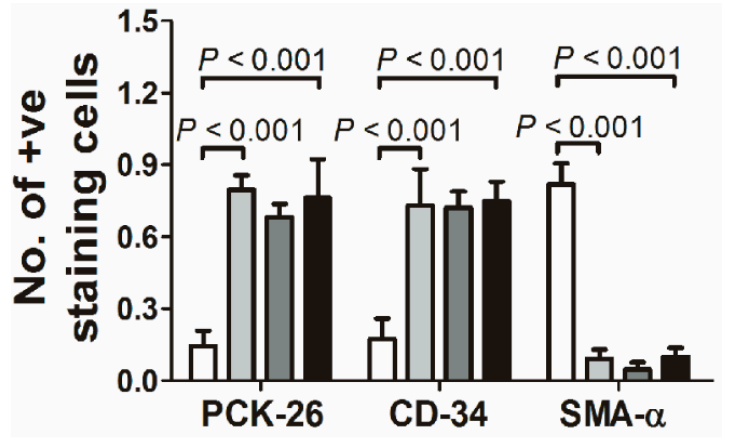

Figure 4. Mouse-derived xenograft model (MDX) to study the effect of combined treatment with capsaicin and H. pylori. (a) Macroscopic analyses of tumor tissue. Tumor images of first (M1) and second passage (M2) tumors showed a high growth rate in SCID mice. Tumors from mice treated with capsaicin and infected with $H$. pylori are represented as M0. The M1 and M2 tumor tissues were similar to M0 in (b) weight and (c) volume $\left(\mathrm{mm}^{3}\right)$. (d) Bodyweight in grams measured per week. Mice were weighed before treatment (week 0 ) and then twice per week for 7 weeks. Mice with M0, M1, and M2 tumors lost weight compared to untreated control mice ( $n=5 /$ cohort). (e) Histological analyses of tumor tissues from mice treated with a combination of capsaicin and H. pylori (M0) with first (M1) and second passage (M2) xenografts. Histochemical analysis of PCK-26 and CD-34 in mouse tumor tissue (MDX) showed strong staining compared to the weak staining of SMA- $\alpha$. A score of 1 denotes the highest staining and expression, whereas a score of 0 indicates negative staining or no expression. Quantitative immunohistochemistry of PCK-26 and CD-34 exhibited high scores in tumor tissues compared to a low score for SMA- $\alpha$. 
2.6. Capsaicin Dose in Mice Resembles Human Capsaicin Consumption and Mimics Stage-Dependent Gastric Cancer Development

To apply our observations to humans, we optimized the mice's intake to reflect human intake to determine the dose-dependent $(0.01 \%-0.5 \%$ or $0.05-2.6 \mathrm{~g} / \mathrm{kg} / \mathrm{day})$ effect of capsaicin. Mice treated with both $H$. pylori and capsaicin developed gastritis, leading eventually to cancer. To confirm this relationship in mice and to establish its relevance in humans, we conducted toxicity experiments in mice and optimized the capsaicin amount to determine its dose-dependent $(0.01 \%-0.5 \%$ or $0.05-2.6 \mathrm{~g} / \mathrm{kg} / \mathrm{day})$ effect. Mice treated with a combination of $H$. pylori infection and capsaicin (at a dose less than $0.06 \%$ or $0.312 \mathrm{~g} / \mathrm{kg} /$ day but greater than $0.05 \%$ or $0.26 \mathrm{~g} / \mathrm{kg} /$ day), which is relevant to a human dose of capsaicin (0.021-0.025 g/kg/day) induced a non-toxic effect. Notably, a dose greater than $0.05 \%$ or $0.26 \mathrm{~g} / \mathrm{kg} / \mathrm{day}$ induced significant toxicity and severe gastric inflammation. In contrast, a dose less than $0.05 \%$ or $0.26 \mathrm{~g} / \mathrm{kg} /$ day did not cause any toxic effect or any significant gastric inflammation in mice (Tables $\mathrm{S} 1$ and S2). As a result, we selected a non-toxic, dose of $0.05 \%$ or $0.26 \mathrm{~g} / \mathrm{kg} / \mathrm{day}$ [8]. These results suggest that capsaicin dosage contributes considerably to the development of gastric inflammation and carcinogenesis.

We also examined capsaicin intake, metabolism, and excretion. We found high blood assimilation of capsaicin in mice treated with capsaicin and H. pylori $(0.023 \pm 0.001 \mathrm{~g} / \mathrm{kg} / \mathrm{day})$ compared to mice treated only with capsaicin $(0.021 \pm 0.001 \mathrm{~g} / \mathrm{kg} /$ day $)$. This observation corresponded with the low dissimilation of capsaicin of urine in the gastric tumor group $(0.0003 \pm 0.00001 \mathrm{~g} / \mathrm{kg} / \mathrm{day})$ compared to the group treated with only capsaicin $(0.0006 \pm 0.0001 \mathrm{~g} / \mathrm{kg} / \mathrm{day}$; Figure S3a). Similar results were found in human samples; gastric cancer patients $(0.003 \pm 0.0002 \mathrm{~g} / \mathrm{kg} / \mathrm{day})$ and chronic gastritis patients $(0.001 \pm 0.0002 \mathrm{~g} / \mathrm{kg} /$ day $)$ showed high levels of capsaicin blood assimilation compared to healthy subjects $(0.0005 \pm 0.0001 \mathrm{~g} / \mathrm{kg} / \mathrm{day} ; p<0.0001$; Figure S3b). These results were consistent with the role of capsaicin consumption in the development of physiological abnormalities and gastric cancer. High levels of capsaicin metabolites in urine following capsaicin consumption may be a sign of gastric tumor development as well. The risk for capsaicin-associated cancer is influenced by the expression of capsaicin metabolizing enzymes, such as 16-hydroxycapsaicin, 17-hydroxycapsaicin, and 16-, 17-dehydrocapsaicin, vanillylamine, and vanillin, which increase the risk for cancers [42-44]. As a result, we propose that capsaicin is a potential carcinogen. Ultimately, we developed a mouse model that utilizes a capsaicin dosage relevant to human capsaicin intake. With this model, gastric tumorigenesis is induced without toxicity in peripheral organs. As a result, this mouse model was used to study the effect of capsaicin and its metabolites on the development of gastric cancer.

\subsection{Capsaicin-Treated and H. pylori-Infected Mouse Tumors Showed Increased Pro-Inflammatory Cell Infiltration}

Gastric inflammation leads to gastric tumor development. In our mouse model, the number of pro-inflammatory cell types was significantly increased (i.e., leukocyte infiltration), as observed by the numbers of activated macrophages (F4/80 positive) and neutrophils (myeloperoxidases, MPO) in mice exhibiting gastric tumors $(0.746 \pm 0.041$ and $0.721 \pm 0.064$, respectively), compared to untreated mice or mice treated with only capsaicin or H. pylori $(p<0.0001$; Figure S4a-b). Noting increased immunocyte infiltration, we analyzed several inflammatory-related chemokines and cytokines at the mRNA and protein (secretion) levels by using a customized multiplex magnetic bead array. In mice treated with capsaicin and $H$. pylori, gastric tumorigenesis was associated with augmented Th1 (IFN- $\gamma$, IL-1 $\beta$, and GM-CSF) and Th2 (IL-10, IL-6, IL-13) cytokine expression ( $p<0.001$; Figure 5a-1). In particular, the pro-inflammatory cytokines IL- 6 and IFN- $\gamma$ showed high and low expression in mice with gastric cancer induced by treatment with capsaicin and $H$. pylori, respectively. Overall, $H$. pylori infection and capsaicin consumption produced great association towards IL- 6 and IFN- $\gamma$ expression. IL- 6 and IFN- $\gamma$ cytokines may play a critical role in the development of gastric inflammation and later gastric cancer. 

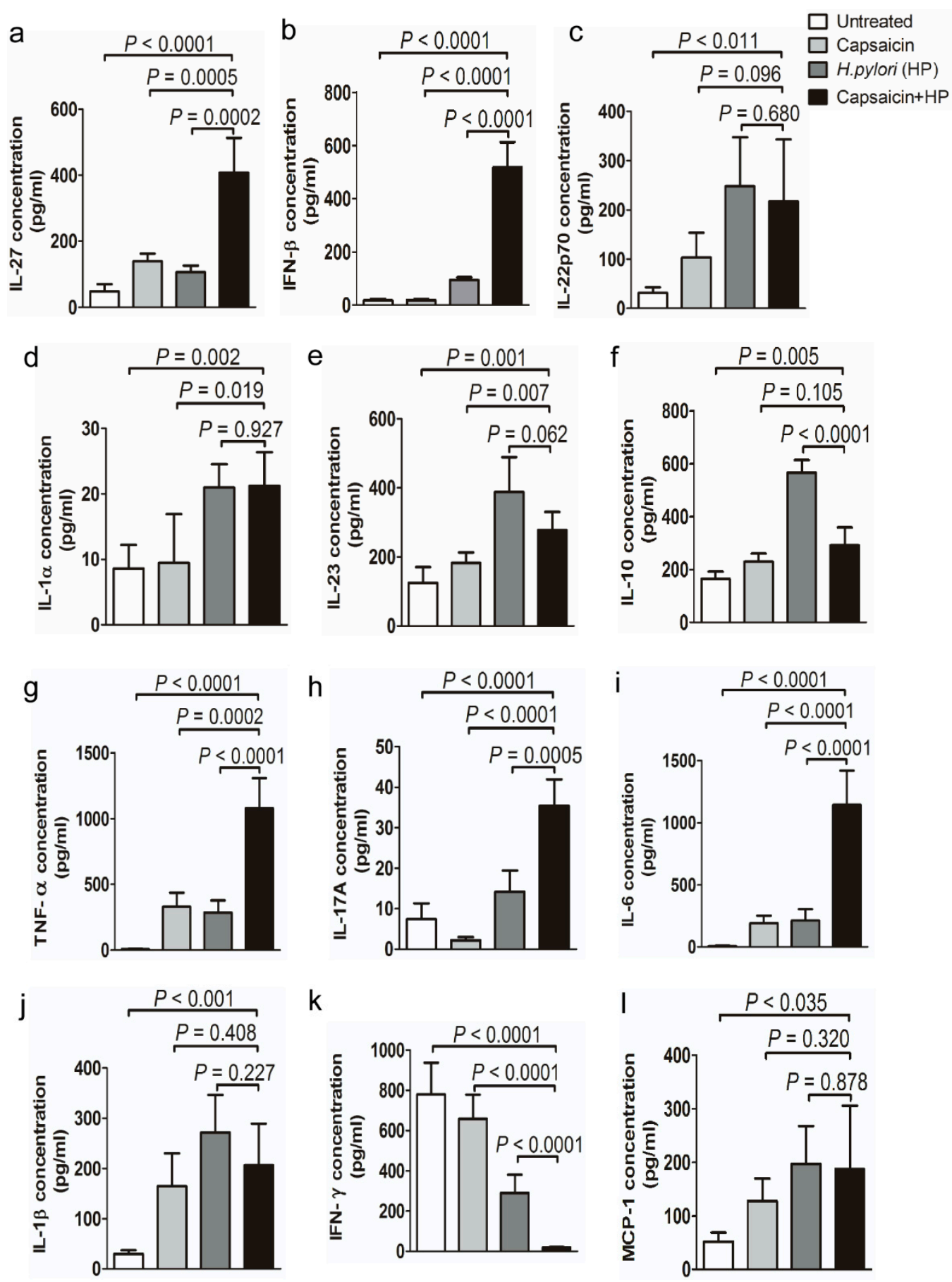

Figure 5. Analysis of cytokines in serum from gastric disease mouse models. Secretory profiles of pro-inflammatory cytokines (a) IL-27, (b) IFN- $\beta$, (c) IL-22P70, (d) IL-1 $\alpha$, (e) IL-23, (f) IL-10, (g) TNF- $\alpha$, (h) IL-17A, (i) IL-6, (j) IL-1 $\beta$, (k) IFN- $\gamma$, and (1) MCP-1 in mouse serum samples measured by multiplex magnetic bead array. Graphs show secreted protein expression relative to serum samples from untreated mice ( $n=5 /$ cohort). 


\subsection{DFMO Prevented H. pylori- and Capsaicin-Induced Gastric Cancers}

We examined the role of IL- 6 and IFN- $\gamma$ in gastric cancer prevention by using the anti-inflammatory agent DFMO (scheme illustrated in Figure $6 \mathrm{~h}$ ). We administered capsaicin and H. pylori to mice, followed by DFMO treatment. Macroscopic morphometric analysis revealed that DFMO (100 and $200 \mathrm{mg} / \mathrm{kg}$ ) inhibited gastric inflammation in a dose-dependent manner and prevented gastric tumorigenesis (Figure 6a,b). Histological analysis also showed multifocal elongation of the gastric pits, glandular atrophy, and a significant reduction in the glandular zone in atrophic foci. These changes were significant in mice treated with capsaicin and infected with $\mathrm{H}$. pylori, exhibiting gastric inflammation $(2.800 \pm 0.200)$ compared to mice treated with DFMO $(200 \mathrm{mg} / \mathrm{kg} ; 1.400 \pm 0.244)$ or untreated $(0.6 \pm 0.245$; $p=0.002$; Figure S5a-d). The anti-inflammatory potential of DFMO against gastritis and, therefore, against gastric cancer was evaluated by analyzing IL- 6 and IFN- $\gamma$ status. We observed a significant dose-dependent decrease and increase in the levels of pro-inflammatory cytokine IL- 6 and IFN- $\gamma$ for DFMO-treated mice compared to untreated mice exhibiting gastritis and to $H$. pylori-eradicated mice $(p<0.0001$; Figure $6 c, d)$, respectively. Moreover, other inflammatory cytokines and chemokines (IL-27, IFN- $\beta$, IL-1 $\alpha$, IL-23, IL-22P70, TNF- $\alpha$, IL-17A, IL-10, IL-1 $\beta$, and MCP-1) were not showed dose-dependent changed in DFMO-treated mice compared to gastritis mice group (Figure S6a-j). In contrast, COX-1 and COX-2 expression was also substantially reduced $(p<0.001$; Figure 6e,f). DFMO-treated mice (100 or $200 \mathrm{mg} / \mathrm{kg}$ ) showed significantly higher body weight compared to mice treated with a combination of capsaicin and H. pylori infection (Figure $6 \mathrm{~g}$ ). This result suggests that DFMO may prevent gastric tumorigenesis induced by a combination of capsaicin consumption and H. pylori infection. DFMO appears to act as an anti-inflammatory agent to prevent capsaicin-associated gastric cancer development by targeting COX- 1 and COX- 2 and by regulating IL- 6 and IFN- $\gamma$ expression. 
a

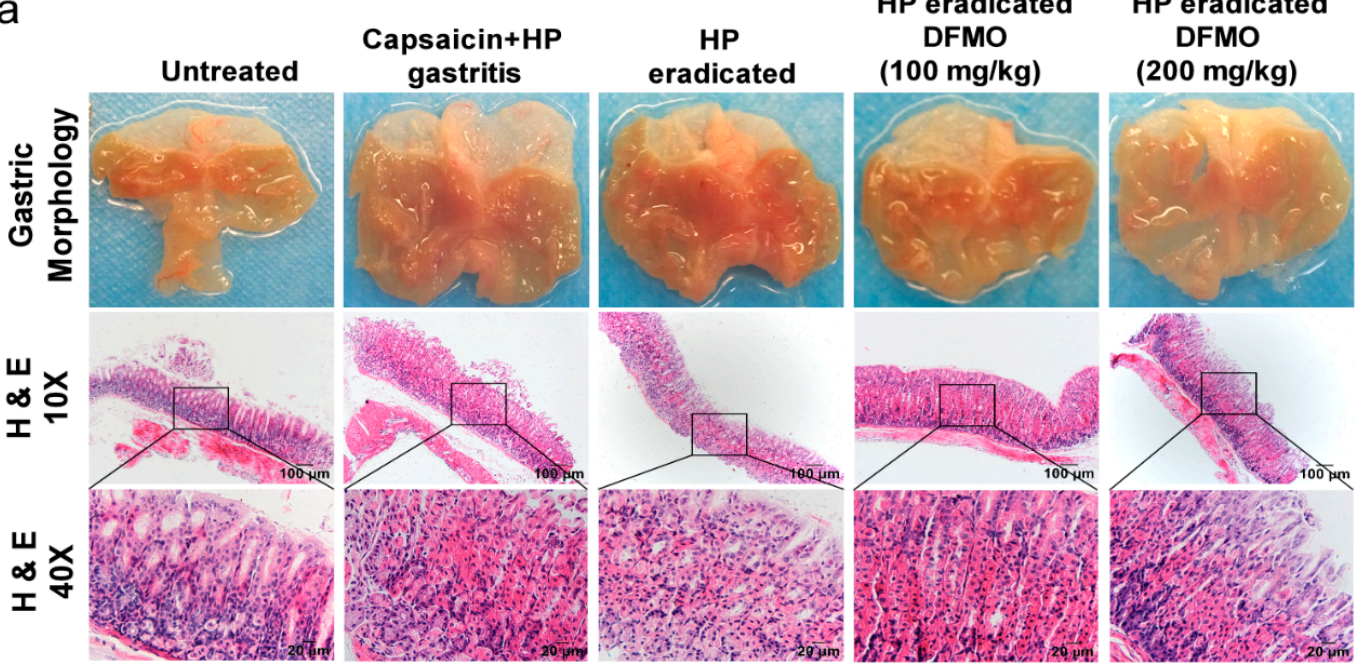

b

C

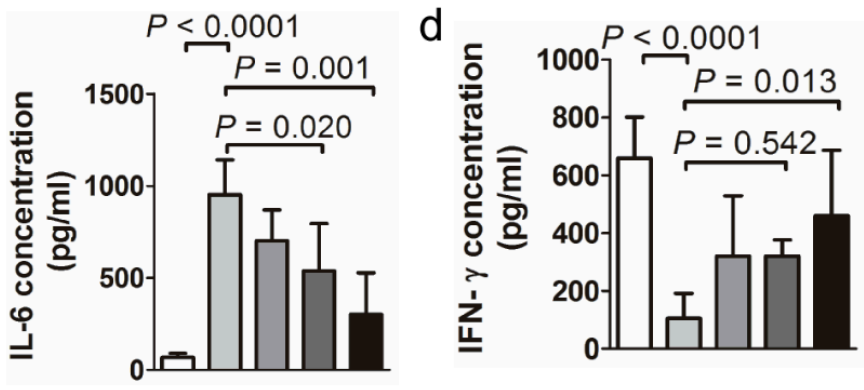

e
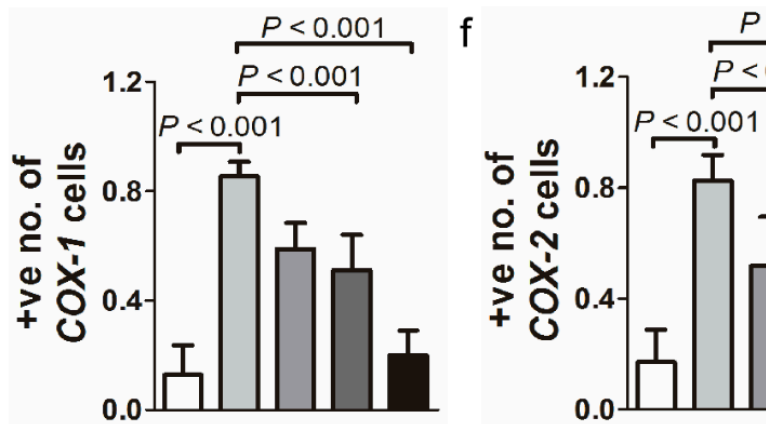

g<smiles>NCCCC(N)(C(=O)O)C(F)F</smiles>
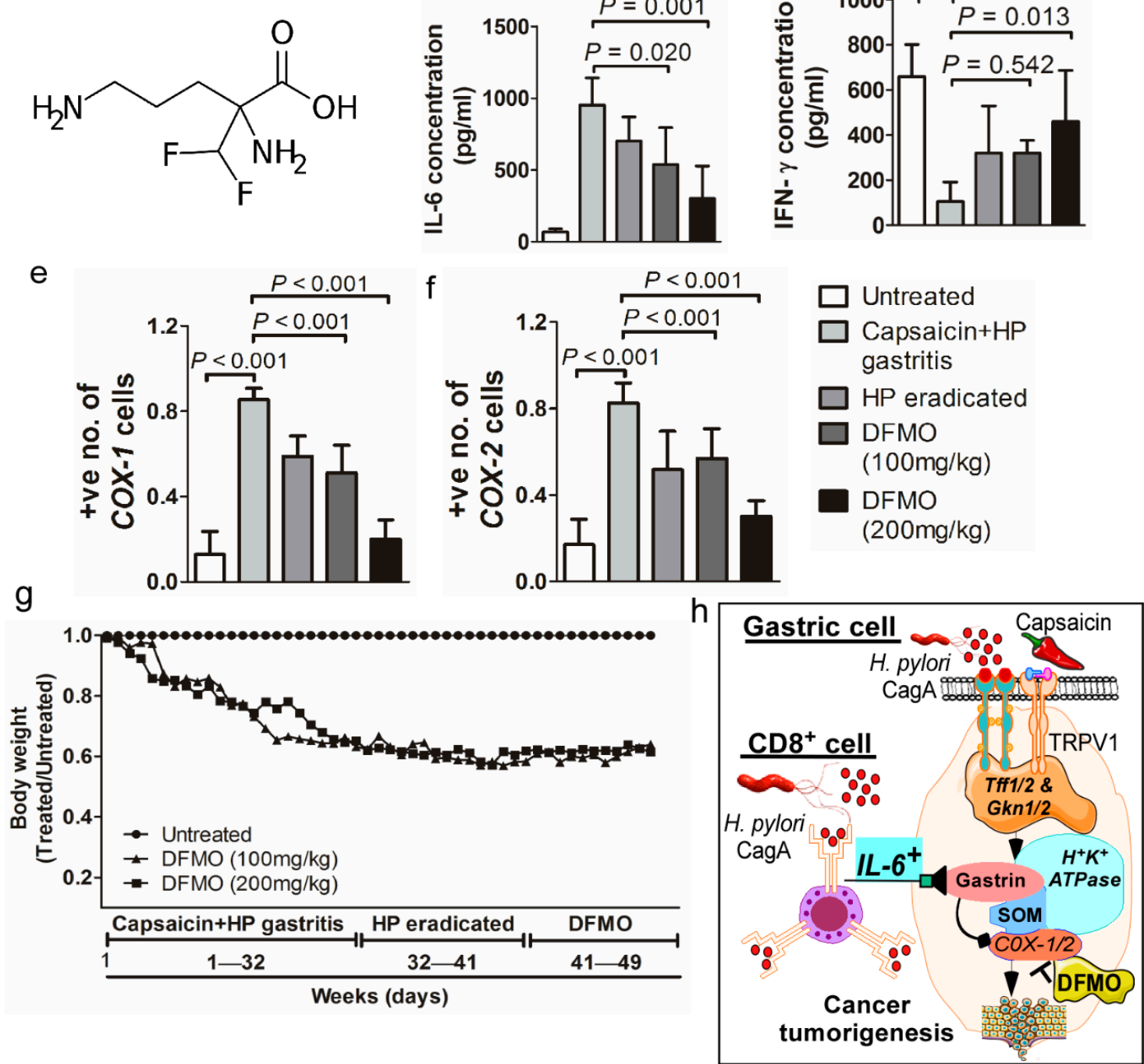

Figure 6. 2-difluoromethylornithine (DFMO) preventive gastritis mouse model. (a) The gastric tissues from mice exhibiting gastritis induced by capsaicin and H. pylori or mice with $H$. pylori that was eradicated and treated with DFMO (100 or $200 \mathrm{mg} / \mathrm{kg}$ ) did not show tumor development ( $n=5 /$ cohort). 
Histological sections were stained with H\&E. The scale bars represent $100 \mu \mathrm{m}(\times 10)$ and the scale bar in the inset images in each panel represents $20 \mu \mathrm{m}(\times 40)$. (b) The chemical structure of DFMO. (c) IL-6, (d) IFN- $\gamma$ secretory protein levels in mouse serum samples were measured by a multiplex magnetic bead array $(n=5)$. Quantitative immunohistochemistry of (e) COX-1 and (f) COX-2 expression in gastric tumors and gastritis tissues. (g) Effect of DFMO 100 and $200 \mathrm{mg} / \mathrm{kg}$ on mouse body weights. Body weights are shown as treated/untreated. Data are expressed as mean values \pm SEM ( $n=5 /$ cohort). (h) A schematic drawing showing the proposed mechanism of capsaicin consumption combined with H. pylori infection in the development and progression of gastritis to gastric tumorigenesis.

\section{Discussion}

Previous epidemiological and meta-analysis studies demonstrated a dose-dependent relationship between capsaicin consumption (30-80 g/day) and an increased risk of developing certain cancers, including stomach cancer [45-47]. Our study provides a biological rationale explaining high gastric cancer incidence in regions with high capsaicin consumption and H. pylori infection. Our mouse model confirms that capsaicin contributes to the induction of gastric inflammation leading to gastric cancer in the presence of H. pylori infection (Figure 1).

Normal gastric mucosal development requires gastrin, somatostatin, and $\mathrm{H}+\mathrm{K}+\mathrm{ATPase}$; however, all three are greatly diminished in mice with gastritis and tumorigenesis (Figure 2). These ablations affect gastric mucosal health and parietal cell activation. Moreover, treatment with a combination of capsaicin and $H$. pylori infection leads to increased peroxidation. This observation suggests that stimulation of gastric inflammation and gastric tumorigenesis involves the production of inflammation-inducing proteins and cytokines (Figure 3). Thus, capsaicin and H. pylori synergistically contribute to accelerated loss of differentiated epithelial cell types, leading to chronic atrophic gastritis and gastric tumorigenesis.

We propose that $H$. pylori regulate pro-inflammatory cytokine production and release of IL-6, IFN- $\gamma$, IL-17A, IL-1 $\beta$, IL-27, and TNF- $\alpha$. This cytokine release causes gastric tissue damage leading to activation of inflammatory cancer signaling pathways (Figure 5). The outcome of IL-6 stimulation suggests that pre-existing gastric immunopathology accelerates the loss of differentiated epithelial cell types, leading to profound glandular atrophy and gastric tumorigenesis. In fact, IL-6 stimulation with IFN- $\gamma$ inhibition may promote the shift from gastric inflammation to gastric carcinogenesis in mice administered both capsaicin and H. pylori (Figure 5). As a result, IL-6 inhibitors can serve as a therapy against gastric cancer, in addition to lowered capsaicin intake and pathogen clearance. Gastritis patients with high IL-6 levels may also benefit from IL-6 inhibition as a preventive measure against gastric carcinogenesis (Figure 5).

Tumorigenesis in C57Balb/c mice is attributed to IL-6 and IFN- $\gamma$ deregulation in capsaicin-treated and $H$. pylori-infected mice. This deregulation leads to reduced expression of Tff1 and Tff2, along with a reduced expression of putative tumor suppressor genes, Gkn1 and Gkn2. Tff1 and Tff2 are important endogenous regulators of gastric homeostasis, and they showed loss of expression during capsaicin exposure and H pylori infection [25,27]. Accordingly, capsaicin and H. pylori are critical regulators of Tff2 and upstream gastrokine gene expression. Tff2 inhibition likely promotes tumor growth due to the loss of anti-proliferative gastrokine and Tff1 genes. Additionally, the human GKN2 protein predominantly exists as a heterodimer with Tff1 [28]; attenuated expression of either protein may potentiate their combined loss of function. Downregulation of both Tff1 and Tff2 expression also frequently occurs in gastric cancers displaying tumor suppressor function. However, loss of Tff1 and Tff2 promotes increased gastric inflammation and accelerates fundic atrophy with significant loss of parietal and chief cell lineages. This finding provides a mechanism for capsaicin-associated gastric cancer cell proliferation [29].

Our data suggest that combined capsaicin exposure and H. pylori infection modulate and imbalance Th1 and Th2 cytokine levels, leading to mucosal inflammation, inhibition of gastric acid secretion, and induction of fundic atrophy. Tumorigenesis in capsaicin- and H. pylori-treated mice was associated with augmented Th1 cytokine release, particularly IL-6, along with attenuated Th2 cytokine expression. Th1 cytokines like IL-6 promote chronic atrophic gastritis and predisposition to tumorigenesis through 
inhibition of gastrin and somatostatin, as indicated earlier (Figure 5). In combination, capsaicin and H. pylori provide a gastric cancer development mechanism in which local immune responses modulate and decrease essential gastric hormones.

Here, the selected anti-inflammatory agent, DFMO (2-difluoromethylornithine) inhibits ornithine decarboxylase (ODC) activity, an enzyme catalyzing a rate-limiting step of polyamine biosynthesis. ODC is necessary for entry into and progression through the cell cycle; additionally, Selvakumaran et al. demonstrated that ODC is a transcriptional target of the $c-m y c$ oncogene [48]. In our mouse model, DFMO acts by inhibiting IL-6 and promoting IFN- $\gamma$ cytokine release (Figure 6 ), plus it enhances antitumor $\mathrm{CD}^{+}{ }^{+} \mathrm{T}$-cell infiltration and augments adoptive T-cell therapy. Furthermore, DFMO impairs the suppressive activity of myeloid-derived suppressor cells (MDSC), reverses tumor-induced immunosuppressive mechanisms, and invokes a measurable antitumor immune response [22,49]. Consequently, DFMO treatment may serve as a preventive measure against gastric tumorigenesis induced by capsaicin consumption and H. pylori infection.

\section{Methods}

\subsection{Preparation of H. pylori Strains}

Helicobacter pylori (H. pylori, Sydney strain or SS1) was provided by Professor Young-Joon Surh (Seoul National University, Seoul, South Korea). H. pylori SS1 was grown on Columbia Agar (Oxoid, Basingstoke, Hampshire, England, Cat number CM0331) plates for $48 \mathrm{~h}$ at $37^{\circ} \mathrm{C}$ under microaerophilic conditions on 7\% lysed horse blood (Solarbio, Beijing Solarbio Science \& Technology, Beijing, China Cat number S9050) agar and antibiotics, including amphotericin B $(1.5 \mu \mathrm{g} / \mathrm{mL}$; Solarbio, Cat number: A8250), trimethoprim $(1.25 \mu \mathrm{g} / \mathrm{mL})$ (Tichea Chemical Industry Development Co, Shanghai, China, Product code T2286), and vancomycin $(2.5 \mu \mathrm{g} / \mathrm{mL})$ (Solarbio, Cat number: V8050). Identification was performed by Gram staining (Solarbio, Cat number G1060) and testing for urease (Nanjing Jiancheng Bioengineering Institute, Nanjing, China; Cat number C013-2), catalase (Nanjing Jiancheng Bioengineering Institute, Cat number A007-1), and molecular markers.

\subsection{Animal Model Experimental Design}

Mice were eight-week-old male C57-BL/6J-219 mice (18-20 g; Beijing Vital River Laboratory, Beijing, China) that were free of Helicobacter spp., Citrobacter rodentium, and Salmonella spp. Mice were maintained under specific pathogen-free conditions and fed sterilized commercial pellet diets (Beijing HFK Bioscience, Beijing, China) and sterile water ad libitum and housed in an air-conditioned biohazard room at a controlled temperature of $24^{\circ} \mathrm{C}$, under a 12-h light/dark cycle. The experiments were performed after protocol approval by the ethics committee of China-US (Henan) Hormel Cancer Institute, Henan, China, and were conducted in accordance with the current guidelines for laboratory animal care. C57-BL/6J-219 (Access No: CUHCI2015011) were randomly assigned to 5 groups of 10 animals each. After one week of acclimation, mice were administered capsaicin $(0.05 \%$ or $0.2 \mathrm{~g} / \mathrm{kg} / \mathrm{day})$ in dietary food for two weeks prior to infection with $H$. pylori, and capsaicin administration was continued throughout the experiment. To facilitate H. pylori colonization, pantoprazole $(20 \mathrm{mg} / \mathrm{kg})$ was administered by gavage 3 times to lower gastric acidity. Each mouse was administered a suspension of the H. pylori SS1 strain containing $10^{8} \mathrm{CFUs} / \mathrm{mL}$ by gavage 3 times per week. Mice $(n=5)$ were euthanized on consecutive weeks of $4,8,12,16,20,24,28,32,36,40,44,48$, and 52 weeks. A control group was maintained without any treatment and was euthanized at the same time as the experimental group. In another mouse model, doses of capsaicin ranging from $0.5-5.0 \mathrm{~g} / \mathrm{kg} /$ day were administered to mice $(n=5)$ to determine the optimal capsaicin dose to induce gastric tumorigenesis. In addition, after confirmation of gastritis development at 32 weeks after $H$. pylori infection, a DFMO-treated gastritis mouse model was developed (Access No: CUHCI2016015). H. pylori were eradicated by administering by gavage a triple regimen of omeprazole $(400 \mu \mathrm{moL} / \mathrm{kg} /$ day; Jiangsu Pengayao Pharmaceutical. Co., Yinxing, Jiangsu, China), metronidazole oral suspension (14.2 mg/kg/day; Guizhou Feiyuling 
Pharmaceutical. Co., Guizhou, China), and clarithromycin granules in oral suspension $(7.15 \mathrm{mg} / \mathrm{kg} / \mathrm{day}$; Xiuzheng Pharmaceutical Co. Changchun, Jilin, China) twice daily for 7 days with a 30-60 min interval between omeprazole and antibiotics. Persistence of gastric inflammation after successful eradication of H. pylori was analyzed after two months (41 weeks). C57-BL/6J-219 mice that still had H. pylori after the eradication therapy were excluded from the analysis. H. pylori colonization and eradication were confirmed by calculating the $\mathrm{Cfu} /$ gram of stomach and colonization assay (urease test) (Figure S7a,b). H. pylori-eradicated mice were divided into two groups based on DFMO dose (100 and $200 \mathrm{mg} / \mathrm{kg}$ groups; 49 weeks; Sigma Aldrich, St. Louis, MO, USA, Cat number 17378). Mice were administered a suspension of DFMO by gavage 3 times a week for 2 months. A toxicity assay was performed to optimize the amount of consumption. Mice $(n=10)$ were administered different amounts of capsaicin $(0.01 \%-0.5 \%$ or $0.05-2.6 \mathrm{~g} / \mathrm{kg} /$ day $)$ up to 3 weeks, and mouse survival rate was analyzed.

Ethics approval and consent to participate: The institutional review board at the China-US (Henan) Cancer Institute approved the study (Access No: CUHCI2015011, CUHCI2016015 and CUHCI2016024). Subjects provided informed consent to be included.

\subsection{Gastric Sample Preparation}

Mice were euthanized, and their stomachs excised and gently rinsed with cold saline. For gastric tumor phenotype analyses, stomachs were opened along the greater curvature and spread out on a polypropylene sheet (Jiangsu Jiangyin Jinfeng Textile Co., Jiangsu, China). The area $\left(\mathrm{mm}^{2}\right)$ of the mucosal erosive lesions was measured, and tumors were macroscopically identified in the gastric mucosae by micro-dissection of gastric tumor tissue. The anterior wall of the pyloric antrum contains the pyloric glands and gastric epithelial cells were cut into several linear strips for quantitative enzyme activity, DNA, RNA, protein, and histological analyses. Other peripheral organs were also collected, including brain, lung, liver, kidney, spleen, colon, and heart, in order to analyze the toxic effect of capsaicin consumption by H\&E-staining.

\subsection{Patients and Gastroendoscopy}

All gastric patients were subjected to gastroendoscopy and examination in the Second Affiliated Zhengzhou University Hospital and Henan Cancer Hospital (Zhengzhou, Henan, China). Blood, urine samples, and tissue biopsies were obtained from consenting patients from the antral and corpus portions of the stomach during gastrointestinal endoscopy and gastric surgery. The patients who donated the primary tumors were completely informed and provided written consent (Access No: CUHCI2015009).

\subsection{Morphometric and Histological Analysis}

Morphometric analysis was performed using Image-J software ((http://rsb.info.nih.gov/ij/index. html); National Institutes of Health, Bethesda, MD, USA). For the histological analysis, tissues examined consisted of a section of the stomach taken from the greater curvature and cut from the fundus to the proximal end of the corpus. Longitudinally bisected half stomachs were retained in buffered formaldehyde sections of $6 \mathrm{~mm}$ and stained with H\&E. These samples were scored depending on the severity of (i) superficial regional disruption of the gastric gland with epithelial cell loss, (ii) neutrophil infiltration \& mononuclear cell infiltration (inflammatory cells), (iii) glandular zone reduction, and (iv) functional atrophy (loss of parietal and chief cells), using a scale ranging from 0 to 4 (0: none; 1 : weak; 2: mild; 3 : moderate; and 4: severe) for each criterion. The sections were assessed by an experienced pathologist without knowledge of the treatments. The presence of mononuclear cell infiltration and polymorphonuclear (PMN) cell infiltration indicated chronic gastritis. The length of the glandular zone, primarily composed of parietal cells, was measured as a proportion of total mucosal thickness. Antral tumor tissues were analyzed with measurement of tumor volume and compared with the controls. 


\subsection{Immunohistochemistry (IHC)}

Paraffin-embedded gastric tissues were analyzed by immunohistochemistry (IHC). Serial sections (4-6 mm each) were deparaffinized in xylene and rehydrated in a capsaicin concentration gradient and evaluated with antibodies to detect $H$. pylori (1:100), pepsinogen I and II (1:100 each), MPO (1:100), F4/80 (1:100), CD-34 (1:100), PCK-26 (1:100), and SMA- $\alpha$ (1:100). Sections were subsequently incubated with their respective secondary antibodies for $30 \mathrm{~min}$ at room temperature. The signal was visualized with peroxidase-labeled streptavidin complexes by DAB, and the sections were briefly counterstained with hematoxylin. The immunohistochemical localization pattern was also recorded by digital imaging (Nikon Ti-DS, Tokyo Japan). The ImageScope (11.1.1.752) software program was used, and the labeling index was calculated as a percentage of positive cells relative to the total number of counted cells.

\subsection{Quantitative Enzyme and Activity Assays}

Quantitative enzyme assays included measurement of malondialdehyde (MDA; Cat number A003-1), myeloperoxidase (MPO; Cat number A044), carbonyl (Cat number A087), lipoperoxidase (LPO), catalase (Cat number A007-1), and urease (Cat number C013-2) and were performed according to the manufacturer's instructions (Nanjing Jiancheng Bioengineering Institute, Nanjing, China).

\subsection{Real-Time RT-PCR}

Total RNA was extracted using a commercial RNA extraction kit (Ambion by Life Technologies, Carlsbad, CA, USA), and cDNA was synthesized by amfiRivert cDNA synthesis platinum master mix (GenDEPOT, Katy, TX, USA, Cat number R5600-200). Real-time PCR (qRT-PCR) was conducted using a 7500 FastDX (Applied Biosystems, MA, USA) and the Power SYBR green PCR master mix (Applied biosystem, Warrington WA1 4SR, UK, Cat number 4367659). Primer IDs and sequences are shown in Table S3.

\subsection{Cytokine and Chemokine Protein Measurement Using a Multiplex Bead Array}

Cytokine and chemokine protein levels in mouse (Cat number 740446) and human (Cat number 740118) serum were measured using a multiplex magnetic bead array kit (customized by BioLegend LEGENDplex, San Diego, CA, USA). The multiplex bead arrays were performed according to the manufacturer's instructions with a minimum detectable concentration varying from $0.96-11.27 \mathrm{pg} / \mathrm{mL}$. The Legendplex (version: 7.0) software program was used to analyze the FACS data, and the cytokine concentrations were calculated in $\mathrm{pg} / \mathrm{mL}$ against standard values.

\subsection{H. pylori CFU Quantification within Mouse Stomachs}

After 1, 3, or 6 weeks, mice were euthanized. Stomachs were halved longitudinally along the greater and lesser curvatures and rinsed in sterile phosphate-buffered saline. Each half was manually disrupted on ice in $750 \mu \mathrm{L}$ of Iso-Sensitest (Oxoid, Basingstoke, UK) broth/15\% glycerol. Cells were serially diluted and plated on Columbia blood agar base plates (Oxoid, Basingstoke, UK, Cat number CM0331), supplemented with 10\% defibrinated horse blood (Solarbio, Beijing, CRP, Cat number S9050), and Dent supplement (Oxoid, Basingstoke, UK, Cat number SR0147E).

\subsection{Urine Collection and Measurement (Metabolic Cage Experiments)}

Capsaicin metabolism and urinary flow rate were determined by placing mice individually in metabolic cages. Mice were allowed a 3-day habituation period to adapt to the environment. Later, food and water intake, urinary flow rate, and body weight were recorded every day. Subsequently, a $12 \mathrm{~h}$ collection ( 9 p.m. to 9 a.m.) of urine was performed to obtain the urinary parameters, including volume, $\mathrm{pH}$, and color. Data were analyzed for capsaicin intake, metabolism, and excretion. Capsaicin content in the serum and urine samples from mice and humans was measured according to the Capsaicin ELISA Commercial kit's instructions (Shanghai Jianglai Biotechnology, Shanghai, P.R.C, Cat number JL22882). 


\subsection{Mouse-Derived Xenograft Model}

A mouse-derived xenograft model was developed from gastric tumor tissue of mice treated with capsaicin (Access No: CUHCI2016024). Tissue samples were placed in a Petri plate containing phosphate-buffered saline (PBS) with $0.1 \mathrm{~mL}$ of penicillin $\left(1 \times 10^{5} \mathrm{U} / \mathrm{mL}\right.$; North China Pharmaceutical, Hebei, China), gentamycin $\left(8 \times 10^{3} \mathrm{U} / \mathrm{mL}\right.$; Kaifeng Pharmaceutical Co., Henan, China), and streptomycin $\left(1 \times 10^{5} \mathrm{U} / \mathrm{mL}\right.$; North China Pharmaceutical, Hebei, China). The tissues were divided into three parts. One portion was implanted into CB17 SCID mice purchased from Beijing Vital River Laboratory (Beijing, China). The second portion was fixed in 10\% formalin, and the third portion was used for protein extraction. The mice were anesthetized using $0.3 \mathrm{~mL}$ of $0.4 \%(w / v)$ pentobarbital sodium $(150 \mu \mathrm{L} / 10 \mathrm{~g}$; Sinopharm Chemical Reagent, Guangdong, China) for every $20 \mathrm{~g}$ of body weight. Then mice were subcutaneously implanted with tissues weighing $0.10-0.12 \mathrm{~g}$ and measuring $\sim 3 \mathrm{~mm}$. Animals were monitored periodically for their weight and tumor growth. A second passage was performed, and the same protocol was followed as described above.

\subsection{Statistical Analysis}

The experiments were randomized and investigators were blinded to histological examination during all experiments. All statistical analyses were performed using Graphpad Prism 5.0 software (San Diego, CA, USA), with differences between groups considered significant with a $p$-value $<0.001$. Data are presented as mean values \pm SEM. Histopathological scores and all other experimental data were compared using a $t$-test (two-sided) or one-way analysis of variance (ANOVA) followed by (post hoc) Newman-Keuls multiple and Tukey multiple comparison tests. The discriminatory ability of markers for gastric cancer was evaluated by receiver operating characteristics Curve (ROC), providing the area under the curve (AUC). All tests were two-sided, and $p$-values $\leq 0.01$ were considered statistically significant. Statistical software IBM SPSS 20.0 (SPSS Inc., Chicago, IL, USA) and R program package (Wirtschafts Universität, Wien, Austria) were used to perform these analyses.

\section{Conclusions}

This study describes mechanisms governing the induction and progression of chronic gastritis to gastric cancer under the inflammatory triggers of $H$. pylori infection and capsaicin exposure. This study also proposes DFMO treatment to prevent gastric cancer through pro-inflammatory IL-6 cytokine inhibition, resulting in diminished gastric inflammation. This study is the first to provide experimental animal evidence showing gastric cancer prevention by DFMO treatment in mice with capsaicin consumption and H. pylori infection. In the future, these mouse models can also facilitate further studies into the molecular mechanisms of chronic gastritis and gastric cancer.

Supplementary Materials: All data needed to evaluate the conclusions of this paper are present in the paper and/or Supplementary Materials. The supplementry data underlying Figure S1a-d: Gastric histology scores in gastric disease mice models, Figure S2a-d: Gastric tumor suppressor gene expression generally decreases in mice treated with both capsaicin and H pylori, Figure S3a,b: Capsaicin consumption in the development of gastric tumorigenesis, Figure S4a-d: Analysis of inflammatory mediators in tissues from the gastric disease mouse models and Figure S5a-d: Gastric histology scores in DFMO preventive gastric disease mice models, Figure S6a-j: Analysis of cytokines in serum from DFMO treated cancer preventive mouse models, Figure S7: Quantification of H. pylori (CFU/g of stomach) and H. pylori urease expression level in gastric mucosa, Table S1: Toxicity assay to optimize the capsaicin concentration for the development of gastritis leading to gastric cancer mice model, Table S2: Dose dependent effect of capsaicin in the development of gastritis to cancer mice model, and Table S3: qRT-PCR primer sequences (mouse) are provided as supplementary data files.

Author Contributions: F.A. designed and performed the experiments, derived the models, and analyzed the data; F.A. and Z.D. conceived the idea. Z.D. supervised the project. F.A., M.X., I.K., and J.M. analyzed the data and interpreted the results. F.A., A.C., and K.M. designed the animal protocol and performed animal experiments. F.A. and Y.G. performed the pathological analysis of mouse tissue samples. F.A. wrote and A.M.B. edited the manuscript. All authors have read and agreed to the published version of the manuscript.

Funding: The project was supported by the National Natural Science Foundation of China (NSFC), Research Grant No. 81750110551. 
Conflicts of Interest: None of the authors declare any competing interests.

\begin{tabular}{ll}
\multicolumn{2}{l}{ Abbreviations } \\
Gkns & Gastrokines \\
H. pylori & Helicobacter pylori \\
IARC & International Agency of Research on Cancer \\
IFN & interferon \\
IL & interleukin \\
LPO & lipoperoxidase \\
MDA & malondialdehyde \\
MDX & mouse xenograft model \\
MPO & myeloperoxidases \\
SMA- $\alpha$ & smooth muscle antigen \\
Tff1 & Trefoil factor1 \\
Tff2 & Trefoil factor2 \\
TNF & tumor necrosis factor \\
TSGs & tumor suppressor genes \\
WHO & World Health Organization
\end{tabular}

\section{References}

1. Helicobacter and Cancer Collaborative Group. Gastric cancer and Helicobacter pylori: A combined analysis of 12 case control studies nested within prospective cohorts. GUT 2001, 49, 347-353. [CrossRef]

2. Ferlay, J.; Shin, H.R.; Bray, F.; Forman, D.; Mathers, C.; Parkin, D.M. Estimates of worldwide burden of cancer in 2008: GLOBOCAN 2008. Int. J. Cancer 2010, 127, 2893-2917. [CrossRef] [PubMed]

3. Aziz, F.; Sherwani, S.K.; Akhtar, S.S.; Kazmi, S.U. Development of an in-house enzyme linked immunosorbent assay based on surface whole cell antigen for diagnosis of Helicobacter pylori infection in patients with gastroduodenal ulcer disease. World J. Microbiol. Biotechnol. 2014, 30, 305-315. [CrossRef] [PubMed]

4. Aziz, F.; Yasmeen, T.; Akhtar, S.S.; Kazmi, S.U. In-House Enzyme-Linked Immunosorbent Assay Based on Helicobacter Pylori sonicate whole cell antigen for diagnosis of Helicobacter Pylori Infection in Pakistan. Int. J. Microbiol. Adv. Immunol. 2013, 1, 24-31.

5. Aziz, F.; Chen, X.; Yang, X.; Yan, Q. Prevalence and correlation with clinical diseases of Helicobacter pylori cagA and vacA genotype among gastric patients from Northeast China. Biomed. Res. Int. 2014, 2014, 142980. [CrossRef] [PubMed]

6. Aziz, F.; Gao, W.; Yan, Q. Fucosyltransferase-4 and Oligosaccharide Lewis Y Antigen as potentially Correlative Biomarkers of Helicobacter pylori CagA Associated Gastric Cancer. Pathol. Oncol. Res. 2017, 23, 173-179. [CrossRef]

7. Aziz, F. The emerging role of miR-223 as novel potential diagnostic and therapeutic strategy for immunological diseases. Cell. Immunol. 2016, 303, 1-6. [CrossRef]

8. Moy, K.A.; Fan, Y.; Wang, R.; Gao, Y.T.; Mimi, C.Y.; Yuan, J.M. Alcohol and tobacco use in relation to gastric cancer: A prospective study of men in Shanghai, China. Cancer Epidemiol. Biomark. Prev. 2010, 19, 2287-2297. [CrossRef]

9. Sonnenberg, A. Differences in the birth-cohort patterns of gastric cancer and peptic ulcer. Gut 2010, 59, 736-743. [CrossRef]

10. Lee, Y.Y.; Derakhshan, M.H. Environmental and lifestyle risk factors of gastric cancer. Arch. Iran. Med. 2013, 16, 358-365.

11. Aziz, F.; Qiu, Y. The role of anti-LeY antibody in the downregulation of MAPKs/COX-2 pathway in gastric cancer. Curr. Drug Targets 2014, 15, 469-476. [CrossRef] [PubMed]

12. López-Carrillo, L.; López-Cervantes, M.; Robles-Díaz, G.; Ramírez-Espitia, A.; Mohar-Betancourt, A.; Meneses-García, A.; López-Vidal, Y.; Blair, A. Capsaicin consumption, Helicobacter pylori positivity and gastric cancer in Mexico. Int. J. Cancer 2003, 106, 277-282. [CrossRef] [PubMed] 
13. Nevius, E.; Srivastava, P.K.; Basu, S. Oral ingestion of Capsaicin, the pungent component of chili pepper, enhances a discreet population of macrophages and confers protection from autoimmune diabetes. Mucosal Immunol. 2012, 5, 76-86. [CrossRef] [PubMed]

14. Iancu, A.D.; Petcu, I.; Radu, B.M.; Radu, M. Capsaicin short term administration effect on different immune parameters. Roum. Arch. Microbiol. Immunol. 2012, 71, 221-254. [PubMed]

15. Beltran, J.; Ghosh, A.K.; Basu, S. Immunotherapy of tumors with neuroimmune ligand capsaicin. J. Immunol. 2007, 178, 3260-3264. [CrossRef] [PubMed]

16. Hwang, M.K.; Bode, A.M.; Byun, S.; Song, N.R. Cocarcinogenic Effect of Capsaicin Involves Activation of EGFR Signaling but Not TRPV1. Cancer Res. 2010, 70, 6859-6869. [CrossRef]

17. Clark, R.; Lee, S.H. Anticancer properties of capsaicin against human cancer. Anticancer Res. 2016, 36, 837-843.

18. Ramos-Torres, Á.; Bort, A.; Morell, C.; Rodríguez-Henche, N.; Díaz-Laviada, I. The Pepper's Natural Ingredient Capsaicin Induces Autophagy Blockage in Prostate Cancer Cells. Oncotarget 2016, 7, 1569-1583. [CrossRef]

19. Georgescu, S.R.; Sârbu, M.I.; Matei, C.; Ilie, M.A.; Caruntu, C.; Constantin, C.; Neagu, M. Capsaicin: Friend or Foe in Skin Cancer and Other Related Malignancies. Nutrients 2017, 9, 1365. [CrossRef]

20. Bode, A.M.; Dong, Z. The Two Faces of Capsaicin. Cancer Res. 2011, 71, 2809-2814. [CrossRef]

21. Travers, M.; Brown, S.M.; Dunworth, M.; Holbert, C.E.; Wiehagen, K.R.; Bachman, K.E.; Foley, J.R.; Stone, M.L.; Baylin, S.B.; Casero, R.A.; et al. DFMO and 5-Azacytidine Increase M1 Macrophages in the Tumor Microenvironment of Murine Ovarian Cancer. Cancer Res. 2019, 79, 3445-3454. [CrossRef] [PubMed]

22. Ye, C.; Geng, Z.; Dominguez, D.; Chen, S.; Fan, J.; Qin, L.; Long, A.; Zhang, Y.; Kuzel, T.M.; Zhang, B. Targeting Ornithine Decarboxylase by $\alpha$-Difluoromethylornithine Inhibits Tumor Growth by Impairing Myeloid-Derived Suppressor Cells. J. Immunol. 2016, 196, 915-923. [CrossRef] [PubMed]

23. Khan, Z.E.; Wang, T.C.; Cui, G.; Chi, A.L.; Dimaline, R. Transcriptional regulation of the human trefoil factor, TFF1, by gastrin. Gastroenterology 2003, 125, 510-521. [CrossRef]

24. Zavros, Y.; Eaton, K.A.; Kang, W.; Rathinavelu, S.; Katukuri, V.; Kao, J.Y.; Samuelson, L.C.; Merchant, J.L. Chronic gastritis in the hypochlorhydric gastrin-deficient mouse progresses to adenocarcinoma. Oncogene 2005, 24, 2354-2366. [CrossRef] [PubMed]

25. Martin, G.; Wex, T.; Treiber, G.; Malfertheiner, P.; Nardone, G. Low-dose aspirin reduces the gene expression of gastrokine- 1 in the antral mucosa of healthy subjects. Aliment. Pharmacol. Ther. 2008, 28, 782-788. [CrossRef]

26. Moss, S.F.; Lee, J.W.; Sabo, E.; Rubin, A.K.; Rommel, J.; Westley, B.R.; May, F.E.B.; Gao, J.; Meitner, P.A.; Tavares, R.; et al. Decreased expression of gastrokine 1 and the trefoil factor interacting protein TFIZ1/GKIM2 in gastric cancer: Influence of tumor histology and relationship to prognosis. Clin. Cancer Res. 2008, 14, 4161-4167. [CrossRef]

27. Resnick, M.B.; Sabo, E.; Meitner, P.A.; Kim, S.S.; Cho, Y.; Kim, H.K.; Tavares, R.; Moss, S.F. Global analysis of the human gastric epithelial transcriptome altered by Helicobacter pylori eradication in vivo. Gut 2006, 55, 1717-1724. [CrossRef]

28. Westley, B.R.; Griffin, S.M.; May, F.E.B. Interaction between TFF1, a gastric tumor suppressor trefoil protein, and TFIZ1, a brichos domain-containing protein with homology to SP-C. Biochemistry 2005, 44, 7967-7975. [CrossRef]

29. Peterson, A.J.; Menheniott, T.R.; O'Connor, L.; Walduck, A.K.; Fox, J.G.; Kawakami, K.; Minamoto, T.; Ong, E.K.; Wang, T.C.; Judd, L.M.; et al. Helicobacter pylori infection promotes methylation and silencing of trefoil factor 2, leading to gastric tumor development in mice and humans. Gastroenterology 2010, 139, 2005-2017. [CrossRef]

30. Ouyang, J.; Pan, X.; Lin, H.; Hu, Z.; Xiao, P.; Hu, H. GKN2 increases apoptosis, reduces the proliferation and invasion ability of gastric cancer cells through down-regulating the JAK/STAT signaling pathway. Am. J. Transl. Res. 2017, 9, 803-811.

31. Yoon, J.H.; Park, Y.G.; Nam, S.W.; Park, W.S. The diagnostic value of serum gastrokine 1 (GKN1) protein in gastric cancer. Cancer Med. 2019, 8, 5507-5514. [CrossRef] [PubMed]

32. Wu, J.Y.; Cheng, C.C.; Wang, J.Y.; Wu, D.C.; Hsieh, J.S.; Lee, S.C.; Wang, W.M. Discovery of Tumor Markers for Gastric Cancer by Proteomics. PLoS ONE 2014, 9, e84158. [CrossRef] [PubMed] 
33. Busch, M.; Dünker, N. Trefoil factor family peptides-Friends or foes? Biomol. Concepts 2015, 6, 343-359. [CrossRef] [PubMed]

34. Emami, S.; Rodrigues, S.; Rodrigue, C.M.; Le Floch, N.; Rivat, C.; Attoub, S.; Bruyneel, E.; Gespach, C. Trefoil factor family (TFF) peptides and cancer progression. Peptides 2004, 25, 885-898. [CrossRef]

35. Aziz, F.; Yang, X.; Wang, X.; Yan, Q. Anti-LeY antibody enhances celecoxib efficacy to treat gastric cancer through downregulation of MAPK/COX-2 signaling pathway; correlation with clinical study. J. Cancer Res. Clin. Oncol. 2015, 141, 1221-1235. [CrossRef]

36. Aziz, F.; Wang, X.; Liu, J.; Yan, Q. Ginsenoside Rg3 induces FUT4-mediated apoptosis in H. pylori CagA-treated gastric cancer cells by regulating SP1 and HSF1 expressions. Toxicol. In-Vitro 2016, 31, 158-166. [CrossRef]

37. Baik, S.-C.; Youn, H.-S.; Chung, M.-H.; Lee, W.-K.; Cho, M.-J.; Ko, G.-H.; Park, C.-K.; Kasai, H.; Rhee, K.-H. Increased Oxidative DNA Damage in Helicobacter pylori-infected Human Gastric Mucosa. Cancer Res. 1996, $56,1279-1282$.

38. Federico, A.; Morgillo, F.; Tuccillo, C.; Ciardiello, F.; Loguercio, C. Chronic inflammation and oxidative stress in human carcinogenesis. Int. J. Cancer 2007, 121, 2381-2386. [CrossRef]

39. Tardieu, D.; Jaeg, J.P.; Deloly, A.; Corpet, D.E.; Cadet, J.; Petit, C.R. The COX-2 inhibitor nimesulide suppresses superoxide and 8-hydroxy-deoxyguanosine formation, and stimulates apoptosis in mucosa during early colonic inflammation in rats. Carcinogenesis 2000, 21, 973-976. [CrossRef]

40. Aziz, F.; Yang, X.; Wen, Q.; Yan, Q. A method for establishing human primary gastric epithelial cells culture from gastric tissue with continuous trace medium. Mol. Med. Rep. 2015, 12, 2939-2944. [CrossRef]

41. Aziz, F.; Yang, X.; Wang, X.; Qiu, Y. Helicobacter pylori infection leads to gastric cancer with the coexpression of Lewis Y and CA724. Glycoconj. J. 2013, 30, 411.

42. Bezerra, D.P.; Soares, A.K.N.; de Sousa, D.P. Overview of the Role of Vanillin on Redox Status and Cancer Development. Oxid. Med. Cell. Longev. 2016, 2016, 9734816. [CrossRef]

43. Aldana-iuit, J.G.; Sauri-duch, E.; Miranda-ham, M.D.L.; Castro-concha, L.A.; Cuevas-glory, L.F.; Vázquez-flota, F.A. Nitrate Promotes Capsaicin Accumulation in Capsicum chinense Immobilized Nitrate Promotes Capsaicin Accumulation in Capsicum chinense Immobilized Placentas. Biomed. Res. Int. 2015, 2015, 794084. [CrossRef] [PubMed]

44. Chanda, S.; Bashir, M.; Babbar, S.; Koganti, A.; Bley, K. In Vitro Hepatic and Skin Metabolism of Capsaicin. Drug Metab. Dispos. 2008, 36, 670-675. [CrossRef] [PubMed]

45. Yang, Y.; Zhang, J.; Weiss, N.S.; Guo, L.; Zhang, L.; Jiang, Y.; Yang, Y. The consumption of chili peppers and the risk of colorectal cancer: A matched case- control study. World J. Surg. Oncol. 2019, 17, 1-7. [CrossRef] [PubMed]

46. Chen, Y.H.; Zou, X.N.; Zheng, T.Z.; Zhou, Q.; Qiu, H.; Chen, Y.L.; He, M.; Du, J.; Lei, H.K.; Zhao, P. High Spicy Food Intake and Risk of Cancer: A Meta - analysis of Case-Control Studies. Chin. Med. J. 2017, 130, 2241-2250. [CrossRef]

47. Lee, K.W. Capsaicin can act as co-carcinogen, study finds. Chili Pepper Compon. Linked Skin Cancer 2020, 2, 3-5.

48. Selvakumaran, B.M.; Hoffman, B.; Society, T.A. The Proto-Oncogene c-myc Blocks Myeloid Differentiation Independently of Its Target Gene Ornithine Decarboxylase. Blood 1996, 88, 1248-1255. [CrossRef]

49. Alexander, E.T.; Minton, A.; Peters, M.C.; Iv, O.P. A novel polyamine blockade therapy activates an anti-tumor immune response. Oncotarget 2017, 8, 84140-84152. [CrossRef]

(C) 2020 by the authors. Licensee MDPI, Basel, Switzerland. This article is an open access article distributed under the terms and conditions of the Creative Commons Attribution (CC BY) license (http://creativecommons.org/licenses/by/4.0/). 